\title{
ESPÍRITO DO PROCESSO CIVIL MODERNO NA OBRA DE RUDCLF VON IHERING
}

\author{
José Rogério Cruz e Tucci \\ Professor Associado do Departamento de Direito Processual \\ da Faculdade de Direito da Universidade de São Paulo
}

Resumo:

Comemora-se, neste mês, o centenário da morte do célebre professor de direito romano, Rudolf von Ihering, ocorrida em Götting, no dia 20 de setembro de 1892. A produção científica de Ihering é caracterizada por dois momentos bem nítidos: o primeiro, pela influência da Escola Histórica (Ihering foi aluno de Savigny); o segundo, pela narração de cunho lógico-estrutural, decorrente da influência do positivismo filosófico. O direito processual, no século XIX, era estudado como mero apêndice do direito civil. Todavia, Ihering, nos escritos de época madura, fundado no lema "pelo direito romano, mas além do direito romano", anteviu e intuiu que, também na esfera do direito processual, a dogmática alemã não poderia ficar eternamente atrelada às fontes romanas clássicas.

Abstract:

The centenary of death of the notable professor of Roman law, Rudolf von Ihering, wich took place, in Göttingen, on September, $20^{\text {th }}$, 1892 , is now celebrated. His scientific production is characterized by the existence of two very distinguished moments: the first, under the influence of the so called Historical School (Ihering had been a pupil of Savigny); the second, filled by logically-structured texts of philosophical-positivism. During the XIX century civil procedure was studied as a mere appendix to civil law. Yet, Ihering, on his writtings of a more mature period, moved by the idea of "for the Roman law, but beyond Roman law", has foreseen that even inside the sphere of civil procedure, the german dogmatism could not remain attached to the classical roman sources.

\section{Sumário:}

1. Introdução.

2. Tendências do processo civil no século XIX.

3. Dimensão social do processo civil.

3.1. Administração da justiça.

3.2. Atributos e garantias do juiz. 
3.3. Igualdade substancial e isonomia processual.

3.4. Sentença e dever de motivação.

4. À guisa de conclusão.

\section{INTRODUÇÃO.}

O meio acadêmico alemão comemora, durante o transcorrer deste mês, o centenário da morte do célebre professor de direito romano, Rudolf von Ihering, ocorrida em Göttingen, no dia 20 de setembro de 1892.

Da personalidade repleta de vida e de alegria de viver do grande cientista homenageado emergiram, segundo anota um de seus biógrafos, autêntica compreensão do papel do jurista, extraordinária capacidade de intuição e um sentimento profundo das tarefas práticas e sociais do direito. ${ }^{1}$

Como escoliasta dos textos romanos, vigentes na Alemanha de seu tempo, Thering foi protagonista de dois momentos cruciais da história políticojurídica do século XIX, que se refletiriam, de modo deveras marcante, em sua vasta produção científica.

Com efeito, culturalmente formado no Vormärz, ou seja, antes de 1848, época de ouro da Escola Histórica, recebe natural influência de Savigny, no tocante à análise e preservação das fontes romanas, e da pandectistica, quanto ao método de exposição. ${ }^{2}$

Com a mudança de rota da ciência jurídica alemã na segunda metade do século passado (Nachmärz), Ihering, do ponto de vista metodológico, abandona a narração de cunho lógico-estrutural e passa a preocupar-se com a funcionalidade do direito.

Influenciado pelo positivismo filosófico, o "último dos romanistas" 3 afasta-se do formalismo abstrato da Escola Histórica, a partir dos conceitos de

1. Franz Wieacker, Storia del diritto privato moderno (trad. ital. Sandro A. Fusco), Milano, Giuffrè, 1980, v. 2, p. 150-1 (= História do direito privado moderno (trad. port. A. M. Botelho Hespanha), Lisboa, Fund. Calouste Gulbenkian, 1980, p. 514).

2. V., a respeito, Mario G. Losano, Introdução à trad. ital. da obra Der Zweck im Recht, Torino, Einaudi, 1972, passim.

3. Cf. John MacDonell e Edward Manson, Rudolf von Ihering, in Great Jurists of the World, London, J. Murray, 1913, p. 590. 
evolução e de escopo, colocando-se como fundador da moderna jurisprudência sociológica. ${ }^{4}$

Examinando o denominado método evolucionista de Ihering, esclareceu o nosso Clóvis Bevilaqua, não ser "possível conhecer o direito de um povo ou de uma época 'simplesmente por sua estrutura anatômica', é preciso vê-lo funcionar, é preciso examinar como foi ele aplicado às relaçōes da vida. Foi o que fez Ihering; e é por esse motivo que ' $O$ espirito do direito romano' difere tão profundamente de todos os tratados, eruditos e minuciosos embora, que expōem dogmaticamente a história do direito romano. Esses tratados nos mostram a evolução da legislação e da doutrina jurídica dos romanos de um modo exato mas sem vida; Thering nol-as veio mostrar 'tal como existiram na realidade', os órgãos em funçāo, a vida em atividade". 5

Dentre as obras principais do Mestre de Berlin e de Göttingen, além da famosa $O$ espírito do direito romano (escrita a partir de 1852) e dos inúmeros ensaios de cunho dogmático estampados no periódico Jahrbücher für die Dogmatik des heutigen römischen und deutschen Privatrechts, por ele fundado, inserem-se $O$ fundamento dos interditos possessórios (1869), $A$ luta pelo direito (1872), $O$ escopo no direito (1877-1884), $A$ vontade na posse (1889) e, ainda, reunido com outros estudos em 1884, o opúsculo intitulado Graça $e$ seriedade na jurisprudência, na qual o humor e a sátira serviram-lhe para solucionar inúmeras questões jurídicas.

\section{TENDÊNCIAS DO PROCESSO CIVIL NO SÉCULO XIX.}

Aluno de Savigny, contemporâneo e amigo de Windscheid, era natural que, com a aproximação dos postulados preconizados pela Escola Histórica, a obra de Ihering fosse dirigida ao estudo das pandectas, uma vez que, em grande parte, o direito romano, cristalizado no Corpus Iuris, encontrava-se de certo modo ainda vigente na Alemanha do século passado.

4. V., amplamente, Losano, Introdução...ob. cit., p. XXXII-XXXIII.

5. Cf. Clóvis Bevilaqua, Rudolf von Ihering, in Juristas philosophos, Bahia, José Luiz da F. Magalhães, 1897, p. 71. V., em senso assemelhado, Peter Stein, Legal evolution: the story of an idea, Cambridge University Press, 1980, p. 67. 
Note-se qLe apesar do processo comum alemão, após a recepção, ter sido moldado pelas fontes romano-canônicas (com pequena influência germânica), continuava grande o interesse pelo processo romano clássico, dando-se, na verdade, pouca ênfase à pesquisa atinente ao direito processual medieval. ${ }^{6}$

Mas a despeito de todas essas circunstâncias, e embora em proporção infinitamente menor, o processo civil passou a ser investigado, a partir da elaboração científica de alguns princípios, desde os fins do século XVIII.

Realmente, os alicerces da ciência processual, como recentemente se afirmoli, ${ }^{7}$ foram erigidos, mesmo antes da importante contribuição de Oskar von Bülow, pelo "tesoro della scienza tedesca dell'Ottocento", nas obras de Grolman, Gönner e Almendingen, ao ser elaborada uma "teoria geral do procedimento" com a enunciação de Prozessmaximen.

Todavia, nessa época, ninguém, na Alemanha, como em nenhuma outra parte do mundo, pensava em estudar o processo como instituição separada da ação, da citação e da defesa (consideradas integrantes do direito civil). ${ }^{8}$

$\mathrm{O}$ "direito das ações" (Aktionenrecht) consistia no estudo da açôes típicas, segundo o modelo traçado pelo direito romano clássico.

Nesse exato sentido, dentre inúmeras contribuições de juristas alemães, especialmente após a descoberta do "Gaio veronês" (1816), Ludwig Keller, em 1827, dedica um livro sobre a litiscontestatio relacionada com a sentença, ${ }^{9}$ colocando em relevo a actio e a exceptio rei iudicatae vel in iudicium deductae do período formular.

6. Destacam-se sobre esse assunto a obra de Savigny (Geschichte des römischen Rechus im Mittelalter, Heidelberg, 1815-1831, vs. 1-7) e, especificamente sobre processo, a de seu aluno Bethmann-Hollweg (Grundriss zu Vorlesungen über den Gemeinen Civilprocess, Berlin, 1821), bem como, de época posterior, as de Wilhelm Endemann (Das deutsche Zivilprozessrecht, Heidelberg, 1868) e de Georg W. Wetzell (System des ordentlichen Zivilprozesses, Leipzig, 1878).

7. V. Knut Wolfgang Nörr, La scuola storica, il processo civile e il diritto delle azioni, Rivista di diritto processuale, n.1, p. 23-4, 1981, explicitando que tais asserções já haviam sido exaradas em sua obra Naturrecht und Zivilprozess, Tübingen, 1976).

8. V., a propósito, a rica exposição de Giovanni Tarello, Dottrine del processo civile: studi storici sulla formazione del diritto processuale civile (Aspetti della dottrina processualistica germanica nel secolo XIX), Bologna, Mulino, 1989, p. 23 e ss..

9. Ueber Litis Contestation und Urtheil nach classischem Römischem Recht, Zürich, Gerner'sche, 1827. 
Como observa Nörr, ${ }^{10}$ o ponto culminante dessa orientação doutrinária é representado pela exposição de Savigny acerca das actiones, das exceções, do concurso de demandas e da prescrição das ações. ${ }^{11}$

Ihering, seguindo a metodologia pandectistica quanto ao conteúdo programático das obras de "direito civil", tratou igualmente das ações como mero apêndice do direito privado.

Após criticar o exacerbado formalismo do processo romano e de discorrer sobre a classificação das ações, sempre dentro da ótica civilista, ocupase dos critérios de identificação ou individualização daquelas, tendo em vista a natureza do direito (pessoal ou real) perseguido pelo demandante. ${ }^{12}$

Ensina, pois, que "seria totalmente ilógico, pretender por meio de dez ações diferentes dez objetos (Gegenstände) oriundos de uma mesma 'stipulatio', tendo o juiz que decidir nos dez processos uma única questão. Sendo idêntico o fundamento (Klaggrund) dos dez processos, os motivos de decidir seriam também os mesmos. Na verdade, nenhuma das questões difere das demais, todas se identificam..." Por outro lado, na esfera do direito de propriedade haverá tantas demandas diferentes quantos forem os objetos, isoladamente considerados... Assim, no âmbito do direito das obrigações, é a causa (Entstehungsgrunde), e nos direitos reais, o objeto (Gegenstände), que determinam a unidade ou a pluralidade da relação... ${ }^{13}$

Em outro de seus trabalhos, Ihering elabora a tese da eficácia reflexa, sustentando que na dimensão jurídica, a exemplo do que ocorre no mundo da fenomenologia da natureza, distinguem-se efeitos diretos, correspondentes ao conteúdo, à determinação e à função do ato jurídico, e efeitos reflexos, não desejados, mas inevitáveis, que afetarão sujeitos diversos

10. Ob. cit., p. 35 .

11. Savigny, Sistema del diritto romano attuale (trad. ital. Vittorio Scialoja), Torino, Utet, 1896, v. 5 . Vale lembrar que no v. 6 dessa monumental obra, Savigny versa sobre os limites da coisa julgada, em que destacado o fenômeno da representação para explicar a extensão dos efeitos da res iudicata a terceiros, teoria essa que hoje pode ser perfeitamente ressuscitada, como material de pesquisa, para examinar os limites subjetivos da coisa julgada nas açōes coletivas...

12. Geist des römischen Rechts auf den verschiedenen Stufen seiner Entwicklung, 3a. ed., Leipzig, Breitkopf Verlag, 1877, v. 3, p. 27 e ss. (= L'esprit du droit romain dans les diverses phases de son développement (trad. franc. Octave de Meulenaere), Paris, A. Marescq, 1878, t. 4, p. 24 e ss.).

13. Ibid., p. 39 (= Ibid., p. 36-7). 
daqueles interessados na eficácia natural do ato, por força de nexos de interdependência existentes entre os relacionamentos jurídicos. ${ }^{14}$

Essa teoria, distinguindo a eficácia jurídica direta da reflexa, embora relativa aos atos jurídicos, foi extremamente prestigiada no campo do direito processual para explicar o intrincado problema dos limites subjetivos da coisa julgada. ${ }^{15}$

Ihering, por outro lado, tinha plena consciência da precocidade das normas processuais em relação àquelas de direito material ("materiellen Gesetze"): "o processo pertence às instituições jurídicas que se desenvolveram em primeiro lugar".

Ressaltava, no entanto, que, com o passar do tempo, o estudo do processo ficou obumbrado pelo grande progresso das "règles du fond du droit": "... Le fond du droit, en seconde lieu, vient témoigner de la préponderance de la procédure, en donnant une tournure propre à toutes ses dispositions qui touchent à la procédure. Nulle aujourd'hui, alors cette influence était très-puissante; les rayons qui illuminaient d'abord la procédure, reflètaient leur lumière sur les dispositions du fond du droit qui la concernaient, laissant les autres institutions dans l'ombre" 16

14. Die Reflexwirkungen oder die Rukwirkung rechtlicher Thatsachen auf dritte Personen, Jahrbücher für die Dogmatik des heuting römischen und deutschen Privatrechts, v. 10, p. 245-275, 1871. Recorde-se que o exemplo que se tornou famoso acerca do aludido fenômeno da vida física é aquele representado pela pedra atirada num lago. Ao redor do ponto em que cai o objeto formam-se vagas concêntricas. "Houve aí um efeito querido e previsto - acertar a pedra em dado lugar do lago; as vagas que se formaram foram efeitos reflexos" (cf. Moacyr Amaral Santos, Primeiras linhas de direito processual civil, 3a. ed., São Paulo, Saraiva, 1979, v. 3, p. 67).

15. V., a propósito, Pasquale Landi, La tutela processuale dell'ambiente, Padova, Cedam, 1991, p. 165, que invoca, dentre outros, o importante ensaio de Carnelutti, Efficacia diretta ed efficacia riflessa della cosa giudicata, in Studi di diritto processuale civile, Padova, Cedam, 1925, v. 1, p. 429 e ss..

16. L'esprit...ob.cit., t. 4, p. 15 e ss. (= Geist des...ob cit., v. 3, p. 17 e ss.). 
$\mathrm{Na}$ verdade, foi somente com Planck ${ }^{17} \mathrm{e}$, mais tarde, com Windscheid, ${ }^{18}$ é que a actio e outros institutos a ela jungidos passam a ser examinados sob um prisma processual, culminando com a obra de Bülow reconhecidamente o mais importante processualista do século passado -, na qual, após sobrelevar as fronteiras que separam o direito material do direito processual, vem concebido o processo como relação jurídica, de natureza pública, autônoma e triangular. ${ }^{19}$

É a partir desse momento, aliás, que se abrem os caminhos para o estudo do processo como ciência.

Protagonista de todas essas vicissitudes e rompido com os postulados individualista e voluntarista da Escola Histórica, Ihering, diante da nova perspectiva de que o "interesse individual deveria subordinar-se ao interesse social" ${ }^{20}$ passa também a encarar o processo como instituição pública com escopos sociais.

\section{DIMENSÃO SOCIAL DO PROCESSO CIVIL.}

3.1. Administração da justiça.

Afirmando que todos os direitos, mesmo aqueles que têm o indivíduo por fim imediato, estão plasmados e vinculados a vertentes sociais, é na obra Der Zweck im Recht que Ihering confere grande relevo à organização judiciária ideal, como garantia externa do direito.

17. Johann Julius Wilhelm von Planck, Die Mehrheit der Rechtsstreigkeiten im Prozessrecht, Göttingen, 1844, p. 121, que, embora utilizando-se do método histórico-sistemático, analisa detidamente vários institutos processuais, como, e. g., o litisconsórcio, com a distinção entre legitimaçāo processual e legitimaçāo de direito substancial.

18. Bernhard Windscheid, Die actio des römischen Civilrecht vom Standpunkte des heutingen Rechts, Düsseldorf, 1856, cuja obra iria dar origem à difundida polêmica travada com T. Muther, ensejando que, da distinção do direito subjetivo material passível de tutela do denominado direito de ação, de natureza pública, o tema da ação fosse definitivamente inserido no contexto do direito processual.

19. Oskar von Bülow, Die Lehre von den Prozesseinreden und die Prozessvoraussetzungen, Giessen, 1868.

20. V., acerca da Interessenjurisprudenz, Enrico Paresce, Ihering Rudolf (von), (verbete), in Novissimo Digesto Italiano, Torino, Utet, 1962, v. 8, p. 152; Bernardo Gesche, Los fines del derecho y las investigaciones juridicas, in Ihering y la lucha por el derecho, Revista de Ciencias Sociales, Universidad de Valparaiso, vs. 10-11, p. 519 e ss., 1976-1977. 
Salienta, de início, que em todos os povos civilizados, numa certa fase da evolução do direito, há uma ruptura entre a justiça e os outros ramos da atividade do Estado: "O poder estatal, isolando a administração da justiça, reconhece, em última análise, que a função do direito tem peculiaridades que lhe são insitas, perante as quais ganham importância garantias diversas daquelas que tutelam as demais atividades". 21

A instituição do juiz prossegue -, corresponde à autolimitação do Estado, significando que o juiz se encontra autorizado a declarar o direito independentemente do poder estatal, segundo seu próprio convencimento, sendo, por isso, vinculante a sentença por ele proferida.

Com efeito, o Estado pode atribuir ao órgão jurisdicional um campo de ação muito restrito ou muito amplo. Mas, dentro dos limites que lhe são outorgados, o juiz é autônomo. Se o poder público avança sobre estes limites, comete uma degeneração do direito, viola a justiça; atacando o ordenamento jurídico por ele mesmo estabelecido, prcclama sua própria decadência... 22

Exatamente pela investidura, autoridade e independência que concede ao juiz, "o poder declara ao povo que renuncia a exercer a função judicial", vale dizer - com palavras do próprio Ihering -, "ao instituir o juiz, (o poder) limita suas prerrogativas sobre parte do direito, cuja realização confia a tal funcionário".

Desse modo, delineia-se evidente que a "simples separação externa da administração da justiça da administração pública representa um progresso de importância vital para o direito". 23

Em seguida, passa Ihering a examinar os componentes necessários que viabilizam a tarefa de distribuir justiça: a aplicação do direito material é tarefa confiada exclusivamente ao juiz, quando duas partes litigantes se submetem a um procedimento rigidamente fixado, que é o processo. "O ponto cardeal da administraçāo da justiça é a lide... Uma lide pressupõe, pois, dois litigantes, ou seja, as partes. No processo civil são partes autor e réu, no penal o

21. Lo scopo nel diritto, Torino, Einaudi, 1972, p. 279.

22. Ibidem. V., a propósito, Agustin Squella Narducci, Derecho y Estado de Derecho en la obra de Rud obra de Rudolf von thering, in Ihering y la lucha... ob. cit., p. 597 e ss..

23. Lo scopo...ob. cit., p. 279. 
ministério público e o acusado. A lide deve ser composta por um terceiro desprovido de qualquer interesse pessoal na decisāo que emitirá..."

3.2. Atributos e garantias do juiz.

Adverte, outrossim, seguindo o raciocínio por último referido, que - "sucesso da administraçāo da justiça repousa exclusivamente em dois pressupostos atinentes à pessoa do juiz, cuja garantia deve, portanto, constituir preocupação central da legislação". O primeiro deles refere-se ao intelecto: o juiz deve ter as roções teóricas necessárias e a habilidade esperada para, num breve espaço de tempo, aplicar o direito. $\mathrm{O}$ segundo, de ordem moral, relacionado com o caráter: o juiz deve possuir a vontade e a coragem moral reclamadas para aplicar o direito sem sofrer influências de qualquer espécie, do ódio e da amizade, da compaixão e do medo (esta é a característica da justiça em sentido subjetivo). ${ }^{24}$

Mas, "inquanto o saber pode ser objeto de coerção; o caráter não: não há meios para impedir a parcialidade do juiz" 25

Para que se evite a indesejável parcialidade do órgão jurisdicional, aduz Ihering que "a independência do juiz da pura discricionariedade do poder estatal, a garantia de sua investidura por força de lei $e$ a inamovibilidade, constituem a garantia da certeza do direito e o indício preciso da seriedade com que o Estado se adequa ao princípio da neutralidade da justiça". Contudo, "para garantir a independência do juiz, não basta a tutela contra a simples perda do cargo, se a função por ele desempenhada não se encontra em grau de torná-lo economicamente independente. Uma das primeiras exigências de uma estrutura viável da administração da justiça é a que propicia ao magistrado uma retribuição suficiente e adequada" ${ }^{26}$

3.3. Igualdade substancial e isonomia processual.

Expondo, em páginas anteriores, o conceito romano de igualdade, salienta o autor do Der Zweck que os juristas clássicos reconheceram o princípio

24. Lo scopo...ob. cit., p. 283.

25. Ibid., p. 284.

26. Ibid., p. 287-8. 
da igualdade como um preceito supremo, embasador da societas. Repudiavam eles a igualdade externa, absoluta, matemática, uma vez que tinham plena convicção da igualdade interna, relativa, geométrica, consistente na idéia de equilibrio entre os membros da sociedade.

$\mathrm{E}$ isso, porque a desigualdade na repartição das vantagens sociais, vale dizer, o dano acarretado ao sócio, significava, na verdade, um dano sofrido pela própria sociedade.

Ora, tal concepção pode ser perfeitamente empregada no que concerne à sociedade civil. O suum cuique deve ser mensurado tendo-se em vista as disposições da lei e de seus pressupostos. "Chamemos de justa a lei que admite tal equilíbrio... Injusta é a lei que, não considerando a discrepância de capacidades, impõe aos pobres os mesmos sacrifícios dos ricos; injusta é a lei que pune os delitos menores com as mesmas penas previstas para os crimes mais graves...". 27

Trasladando tais idéias para o campo do processo, escreve Ihering que a "relaçāo entre as partes e o juiz é uma relação de subordinação jurídica, enquanto aquela entre as partes é uma relação de igualdade jurídica. Até mesmo o poder estatal quando figura como parte num processo civil ou penal, encontra-se juridicamente subordinado ao juiz: posta-se no mesmo patamar do privado, é uma parte como todas as demais".

No âmbito do processo, portanto, o vínculo existente entre as partes as coloca em perfeita igualdade; ou seja, "as armas com que se combatem devem ser iguais, as luzes e as sombras igualmente repartidas. É esta a primeira de todas as exigências que devem informar a organização do processo; é a exigência da justiça processual, a qual, ainda uma vez, coincide com a igualdade: em relação a esta, todas as outras exigências são secundárias...".28

\subsection{Sentença e dever de motivação.}

Concluindo a narração acerca da prestação jurisdicional, vem destacada a imperiosidade de o juiz ater-se ao ordenamento jurídico (legalismo do processo). Tal regra, elevada a verdadeiro postulado do direito processual,

27. Lo scopo...ob. cit., p. 266-8.

28. Ibid., p. 282. 
especialmente no que respeita à sentença, reclama estrita conformidade entre a atuação do juiz e as normas de direito material.

Com o "intuito de excluir o arbitrio judiciário e desejando que o juiz nāo olvide como o seu poder corresponde à mesma medida que a da lei que lhe confere, o princípio supramencionado tem o condâo de obstar consideravelmente a formação de direito extravasador da lei, por obra da praxe...".

Assim sendo, é bem de ver que "o dever de expor a motivaçāo da sentença representa, para o direito civil, uma forma incomparavelmente mais oportuna. Tem, com efeito, o condāo de constringir o juiz a justificar objetivamente a própria sentença, sem que se lhe imponha irrestrita adesão ao conteúdo imediato da lei". 29

\section{4. À GUISA DE CONCLUSÃO.}

Pautando-se no ideário desenhado, em 1857, no programa da revista (Iheringsjahrbücher) por ele fundada e dirigida, e que pode ser sintetizado no lema "pelo direito romano, mas além do direito romano", Ihering não apenas procurou, em seus escritos de época madura, substituir um método por outro, mas, sim, alargar os horizontes do direito alemão, libertando-o do ius romanorum.

Ihering não chegou a conhecer a profecia de Klein acerca dos fins sociais reservados ao processo civil, ${ }^{30}$ mas, sem dúvida, diante da clareza e modernidade da concepção acima exposta, colhida em sua obra preferida, ${ }^{31}$

29. Lo scopo...ob. cit., p. 280-1.

30. Franz Klein, pai do ZPO austríaco de 1895 , concebeu o processo civil como uma Wohlfahrtseinrichtung, ou seja, uma instituiçāo voltada para o "bem estar social", segundo vem afirmado no capítulo intitulado Escopos do processo austríaco, de seu livro Der Zivilprozess Österreichs (Mannheim, 1927, p. 186 e ss.). V. sobre a importância da obra desse insigne jurista, Rainer Sprung, Le basi del diritto processuale civile austriaco, Rivista di diritto processuale, n. 1, p.24 e ss., 1979; Cappelletti, Ideologie nel diritto processuale, in Processo e ideologie, Bologna, Mulino, 1969, p. 19 e ss.; Calamandrei, L'opera di Francesco Klein e il processo civile austriaco, Rivista di diritto processuale civile, n. 1, p. 80-3, 1925.

31. Escrevendo a um amigo, em 30 de abril de 1883, Ihering alude ao Zweck im Recht do seguinte modo: "Esta obra, e não 'O espírito do direito romano', contém o resultado de toda a minha vida científica. Só a compreenderão quando estiver concluída. $O$ espírito do direito romano não passa, na minha mente, de uma preparação. Mas, 'O espírito do direito romano' devia ser escrito para encetar este estudo, cuja elaboração encerra a minha suprema missão científica" (apud Abelardo Saraiva da Cunha Lobo, Rudolf von Ihering e sua grande obra, Revista da Faculdade Livre de Direito, Rio de Janeiro, v.14, p. 159, 1918). 
intuiu e anteviu que, também na esfera do direito processual, a dogmática alemã não poderia ficar eternamente atrelada às fontes romanas clássicas.

Embora só nos estertores do século, com Mortara, é que a "ação judiciária civil" viria definitivamente conceituada como "uma relaçāo de direito público, decorrente do contraste entre sujeitos privados, tendo como objeto matéria de direito subjetivo e desenvolvendo-se no processo mediante a aplicação da norma legal por atuação e autoridade do magistrado", 32 é possível afirmar-se, sem qualquer exagero, que o germe desse posícionamento já se encontrava na construção científica do jurista ora homenageado, para quem, em última análise, o processo deveria ser visualizado como ramo autônomo do direito público, assentado na jurisdição, como manifestação da soberania do Estado moderno...

\section{BIBLIOGRAFIA}

BETHMANN-HOLLWEG, Moritz August von. Grundriss zu Vorlesungen über den Gemeinen Civilprocess. Berlin, 1821.

BEVILAQUA, Clóvis. Rudolf von Ihering. In: Juristas philosophos. Bahia : José Luiz da F. Magalhães, 1897.

BÜLOW, Oskar von. Die Lehre von den Prozesseinreden und die Prozessvoraussetzungen. Giessen, 1868.

CALAMANDREI, Piero. L'opera di Francesco Klein e il processo civile austriaco. In: Rivista di diritto processuale civile, n. 1, 1925.

CAPPELLETTI, Mauro. Ideologie nel diritto processuale. In: Processo e ideologie. Bologna : Mulino, 1969.

CARNELUTTI, Francesco. Efficacia diretta ed efficacia riflessa della cosa giudicata. In: Studi di diritto processuale civile. Padova : Cedam, 1925. v. 1.

ENDEMANN, Wilhelm. Das deutsche Zivilprozessrecht. Heidelberg, 1868.

GESCHE, Bernardo. Los fines del derecho y las investigaciones juridicas. Revista de Ciencias Sociales, Universidad de Valparaiso, n. 10-11, 19761977.

32. Cf. Lodovico Mortara, Commentario del Codice e delle leggi di procedura civile, 2a. ed., Milano, Vallardi, 1923, v.2, p. 538 (a 1a. ed. é de 1900). V., sobre a importância da contribuiçẫo de Mortara para a ciência do processo, Salvatore Satta, Dalla procedura civile al diritto processuale civile, Rivista trimestrale di diritto e procedura civile, 1964, p. 28 e ss.. 
IHERING, Rudolf von. Die Reflexwirkungen oder die Rukwirkung rechtlicher Thatsachen auf dritte Personen. In: Jahrbücher für die Dogmatik des heuting römischen und deutschen Privatrechts, n. 10, 1871.

-.---. Geist des römischen Rechts auf den verschiedenen Stufen seiner Entwicklung. $3^{\mathrm{a}}$ ed. Leipzig : Breitkopf Verlag, 1877. v. 3.

----.. L'esprit du droit romain dans les diverses phases de son développement (trad. franc. Octave de Meulenaere). Paris : A. Marescq, 1878. t. 4.

---.-. Lo scopo nel diritto (trad. ital. Mario G. Losano). Torino : Einaudi, 1972.

KELLER, Ludwig. Ueber Litis Contestation und Urtheil nach classischem Römischem Recht. Zürich : Gerner'sche, 1827.

KLEIN, Franz. Der Zivilprozess Österreichs. Mannheim, 1927.

LANDI, Pasquale. La tutela processuale dell'ambiente. Padova : Cedam, 1991.

LOBO, Abelardo Saraiva da Cunha. Rudolf von Ihering e sua grande obra.

Revista da Faculdade Livre de Direito, Rio de Janeiro, v. 14, 1918.

LOSANO, Mario G. Introdução à trad. ital. da obra Der Zweck im Recht. Torino : Einaudi, 1972.

MACDONELL, John e MANSON, Edward. Rudolf von Ihering. In: Great jurists of the world. London: J. Murray, 1913.

MORTARA, Lodovico. Commentario del Codice e delle leggi di procedura civile. $2^{\mathrm{a}}$ ed. Milano : Vallardi, 1923. v. 2.

NARDUCCI, Agustin S. Derecho y Estado de Derecho en la obra de Rudolf von Ihering. Revista de Ciencias Sociales, Universidad de Valparaiso, v. 10/11, 1976-1977.

NÖRR, Knut W. La scuola storica, il processo civile e il diritto delle azioni. Rivista di diritto processuale, n. 1, 1981.

PARESCE, Enrico. Ihering Rudolf (von). In: Novissimo digesto italiano. Torino : Utet, 1962. v. 8.

PLANCK, Johann J. W. von. Die Mehrheit der Rechtsstreigkeiten im Prozessrecht. Göttingen, 1844.

SANTOS, Moacyr Amaral. Primeiras linhas de direito processual civil. $3^{\mathrm{a}}$ ed. São Paulo : Saraiva, 1979. v. 3.

SATTA, Salvatore. Dalla procedura civile al diritto processuale civile. Rivista trimestrale di diritto e procedura civile, 1964. 
SAVIGNY, F. Carl von. Geschichte des römischen Rechts im Mittelalter. Heidelberg, 1815-1831. vs. 1-7.

----. Sistema del diritto romano attuale (trad. ital. Vittorio Scialoja). Torino : Utet, 1896. v. 5.

SPRUNG, Rainer. Le basi del diritto processuale civile austriaco. Rivista di diritto processuale, v. 1, 1979.

STEIN, Peter. Legal evolution: the story of an idea. Cambridge University Press, 1980.

TARELLO, Giovanni. Dottrine del processo civile: studi storici sulla formazione del diritto processuale civile (Aspetti della dottrina processualistica germanica nel secolo XIX). Bologna : Mulino, 1989.

WETZELL, Georg W. System des ordentlichen Zivilprozesses. Leipzig, 1878.

WIEACKER, Franz. Storia del dirito privato moderno (trad. ital. Sandro A. Fusco). Milano : Giuffrè, 1980. v. 2.

----. História do direito privado moderno (trad. port. A. M. Botelho Hespanha). Lisboa : Fund. Calouste Gulbenkian, 1980.

WINDSCHEID, Bernhard. Die actio des römischen Civilrecht vom Standpunkte des heutingen Rechts. Düsseldorf, 1856. 